\title{
Beating-heart patch closure of muscular ventricular septal defects under real-time three-dimensional echocardiographic guidance: A preclinical study
}

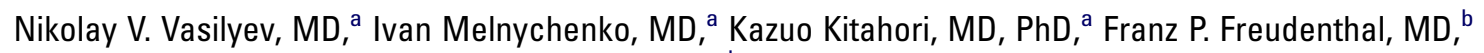
Alistair Phillips, MD, ${ }^{\mathrm{c}}$ Rainer Kozlik-Feldmann, MD, ${ }^{\mathrm{d}}$ Ivan S. Salgo, MD, MS, ${ }^{\mathrm{e}}$ Pedro J. del Nido, MD, ${ }^{\mathrm{a}}$ and Emile A. Bacha, MD ${ }^{a}$

Video clip is available online.
From the Departments of Cardiac Surgery and Anesthesia, ${ }^{\text {a }}$ Children's Hospital Boston, Harvard Medical School, Boston, Mass; the Department of Pediatric Cardiology, ${ }^{\text {b }}$ Kardiozentrum, La Paz, Bolivia; the Department of Pediatric Cardiothoracic Surgery, ${ }^{\mathrm{c}}$ Columbus Children's Hospital, Columbus, Ohio; the Department of Pediatric Cardiology, ${ }^{\mathrm{d}}$ Grosshadern University Hospital, University of Munich, Munich, Germany; and the Ultrasound Division, Philips Medical Systems, Andover, Mass.

Supported in part by National Institute of Health grants no. HL-073647 and HL71128 (PJdN).

Ivan Salgo is employed by Philips Healthcare.

Address for reprints: Emile A. Bacha, MD, Department of Cardiac Surgery, Children's Hospital Boston, Harvard Medical School, 300 Longwood Avenue, Boston, MA 02115 (E-mail: emile.bacha@cardio. chboston.org).

J Thorac Cardiovasc Surg 2008;135:603-9 0022-5223/\$34.00

Copyright $\odot 2008$ by The American Association for Thoracic Surgery

doi:10.1016/j.jtcvs.2007.09.045
Objectives: Safe and effective device closure of ventricular septal defects remains a challenge. We have developed a transcardiac approach to close ventricular septal defects using a patch delivery and fixation system that can be secured under realtime three-dimensional echocardiographic guidance.

Methods: In Yorkshire pigs $(\mathrm{n}=8)$ a coring device was introduced into the left ventricle through a purse-string suture placed on the left ventricular apex, and a muscular ventricular septal defect was created. The patch deployment device containing a 20$\mathrm{mm}$ polyester patch was advanced toward the ventricular septal defect through another purse-string suture on the left ventricular apex, and the patch was deployed under real-time three-dimensional echocardiographic guidance. The anchor delivery device was then introduced into the left ventricle through the first purse-string suture. Nitinol anchors to attach the patch around the ventricular septal defect were deployed under real-time three-dimensional echocardiographic guidance. After patch attachment, residual shunts were sought by means of two-dimensional and three-dimensional color Doppler echocardiography. The heart was then excised, and the septum with the patch was inspected.

Results: A ventricular septal defect was created in the midventricular $(n=4)$, anterior $(\mathrm{n}=2)$, and apical $(\mathrm{n}=2)$ septum. The mean size was $9.8 \mathrm{~mm}(8.2-12.0 \mathrm{~mm})$, as determined by means of two-dimensional color Doppler scanning. The ventricular septal defects were completely closed in 7 animals. In one a $2.4-\mathrm{mm}$ residual shunt was identified. No anatomic structures were compromised.

Conclusions: Beating-heart perventricular muscular ventricular septal defect closure without cardiopulmonary bypass can be successfully achieved by using a catheterbased patch delivery and fixation system under real-time three-dimensional echocardiographic guidance. This approach might be a better alternative to cardiac surgery or transcatheter device closure.

A lthough pediatric cardiopulmonary bypass and cardiac repair of intracardiac defects have matured over the last decades, becoming relatively safe, they remain invasive procedures associated with the potential, albeit rare, for neurologic complications among other complications. ${ }^{1}$ At the same time, there is an increasing amount of basic, translational, and clinical research currently being conducted in the area of beating-heart repairs, including transapical aortic valve and perventricular pulmonary valve implantation, ${ }^{2-4}$ transcardiac ventricular septal defect (VSD) closure, ${ }^{5,6}$ and mitral valvuloplasty and atrial septal defect (ASD) closure. ${ }^{7-9}$ A key component enabling such procedures is the advance in imaging technology, which allows real-time visualization of heart structures and instruments while the heart is beating. Three-dimensional ultrasonographic (3DUS) imaging has made significant progress in the past few years, with improvements in spatial and temporal 


$$
\begin{aligned}
& \text { Abbreviations and Acronyms } \\
& \begin{aligned}
\text { ASD } & =\text { atrial septal defect } \\
\text { LV } & =\text { left ventricle } \\
\text { RT3DE } & =\text { real-time three-dimensional echocardiography } \\
\text { 3D } & =\text { three-dimensional } \\
\text { 3DUS } & =\text { three-dimensional ultrasonography } \\
\text { VSD } & =\text { ventricular septal defect }
\end{aligned}
\end{aligned}
$$

resolution. The ease of data acquisition, real-time three-dimensional (3D) volume rendering, the ability to focus on a specific anatomic structure, and a variety of additional quantification tools have enabled virtually routine application of 3DUS in cardiology practice. ${ }^{10,11}$ Real-time 3D echocardiography (RT3DE) is an ideal imaging modality for septal defect closure because it provides precise anatomic images of complex anatomic structures, such as the atrial or ventricular septum and margins of septal defects. Obstacles to application of 3DUS, such as acoustic interference from metallic instruments caused by shadowing and side-lobe artifacts in the field of view, can be minimized with instrument modifications, such as the application of surface coating and by varying the angle of instrument navigation with respect to the ultrasonographic probe. ${ }^{12}$ The high frame rates currently achieved with RT3DE obviate the need for electrocardiographic or respiratory gating for image acquisition. We have recently demonstrated that epicardial RT3DE provides adequate anatomic detail for surgical task performance in an in vitro model $^{7}$ and in vivo model of beating-heart patch ASD closure. ${ }^{8,9}$

The aim of the present animal study was to investigate the feasibility and efficacy of beating-heart transcardiac closure of a muscular VSD by using our patch delivery and minianchor deployment system under RT3DE guidance.

\section{Materials and Methods}

The experimental protocol was approved by the Children's Hospital Boston Institutional Animal Care and Use Committee. All animals received humane care in accordance with the 1996 "Guide for the care and use of laboratory animals" recommended by the US National Institutes of Health.

Yorkshire pigs ( $70-80 \mathrm{~kg}, \mathrm{n}=8$ ) were anesthetized by means of intramuscular injection of tiletamine/zolazepam $(7 \mathrm{mg} / \mathrm{kg})$ and xylazine $(4 \mathrm{mg} / \mathrm{kg})$. The animals were intubated with a cuffed endotracheal tube and ventilated with a pressure-control ventilator (Healthdyne 105; Healthdyne Technologies, Marietta, Ga); anesthesia was maintained with $1 \%$ to $2 \%$ isoflurane. The electrocardiogram and arterial blood pressure were continuously monitored. A left anterolateral thoracotomy in the fourth intercostal space was performed, and stay sutures were placed on the pericardium to optimize access to the left ventricle (LV) free wall and the apex. RT3DE was performed by using the X4 matrix probe on a SONOS 7500 system (Philips Medical Systems, Andover, Mass). The ultrasonographic probe was inserted into a sleeve (CIVCO Medical Instruments, Kalona,
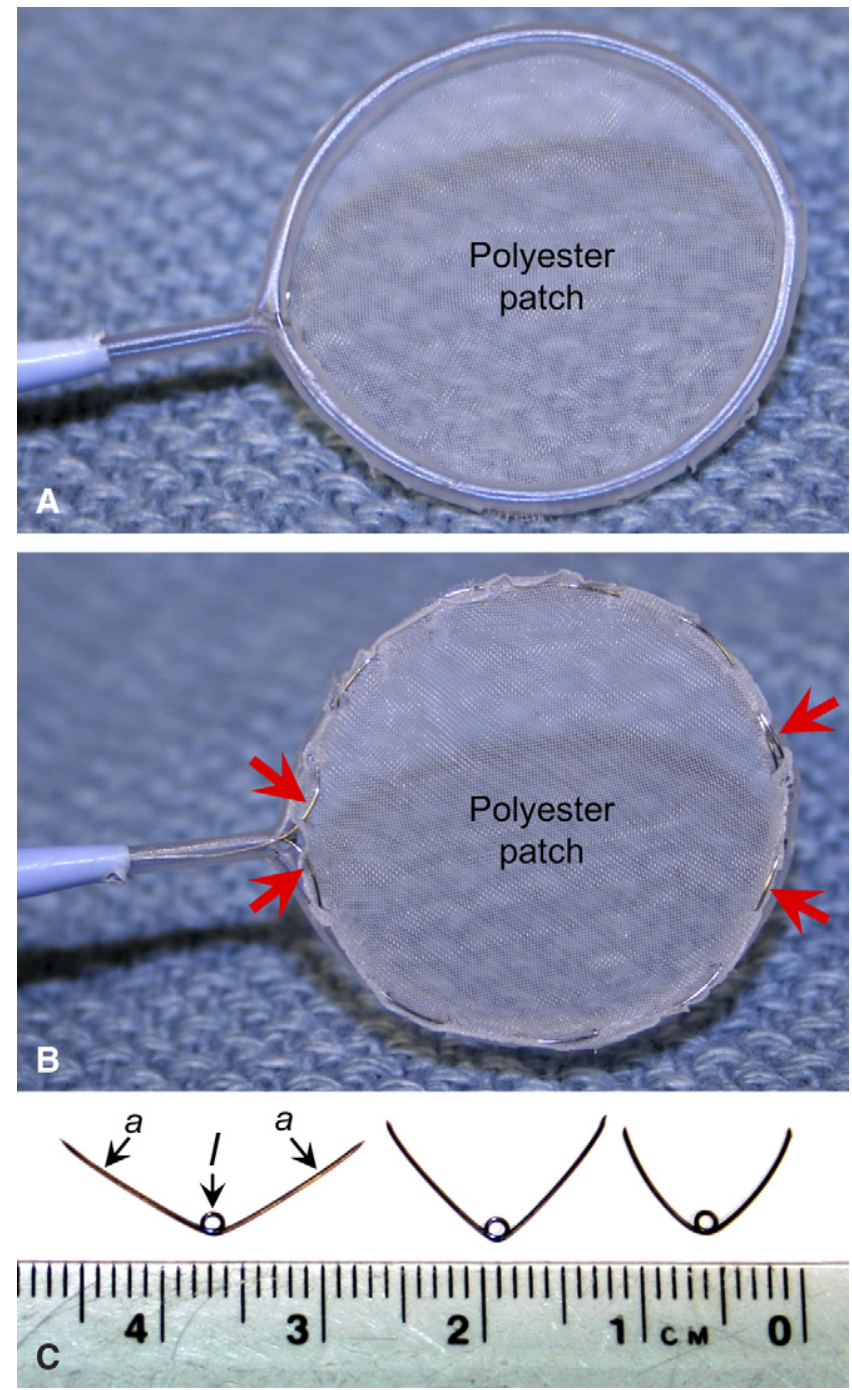

Figure 1. Patch deployment device: front view (A), rear view (B), and minianchors (C). Polyester patch material is attached to the nitinol frame by using a $0.1-\mathrm{mm}$ release nitinol wire (red arrows). During deployment, the arms of the anchor (a) penetrate the patch and attach it to the septal tissue, while the loop (I) stays on the front side of the patch.

Iowa) filled out with an ultrasound gel (Parker Laboratories, Inc, Fairfield, NJ) providing approximately $2 \mathrm{~cm}$ of standoff. The outer surface of the sleeve was lubricated with $0.9 \%$ sodium chloride solution and applied to the surface of the LV. After intravenous heparin administration (100 U/kg), a VSD was created solely under RT3DE guidance. Through a 3-0 polypropylene felt pledget-reinforced purse-string suture placed on the apical portion of the left ventricular free wall, an original 10-mm coring device was introduced into the LV and advanced through the ventricular septum. This created a muscular VSD, which was confirmed by means of two-dimensional (2D) and 3D color Doppler echocardiography.

The VSD was then closed with a polyester patch by using our previously described patch delivery and fixation system, as 


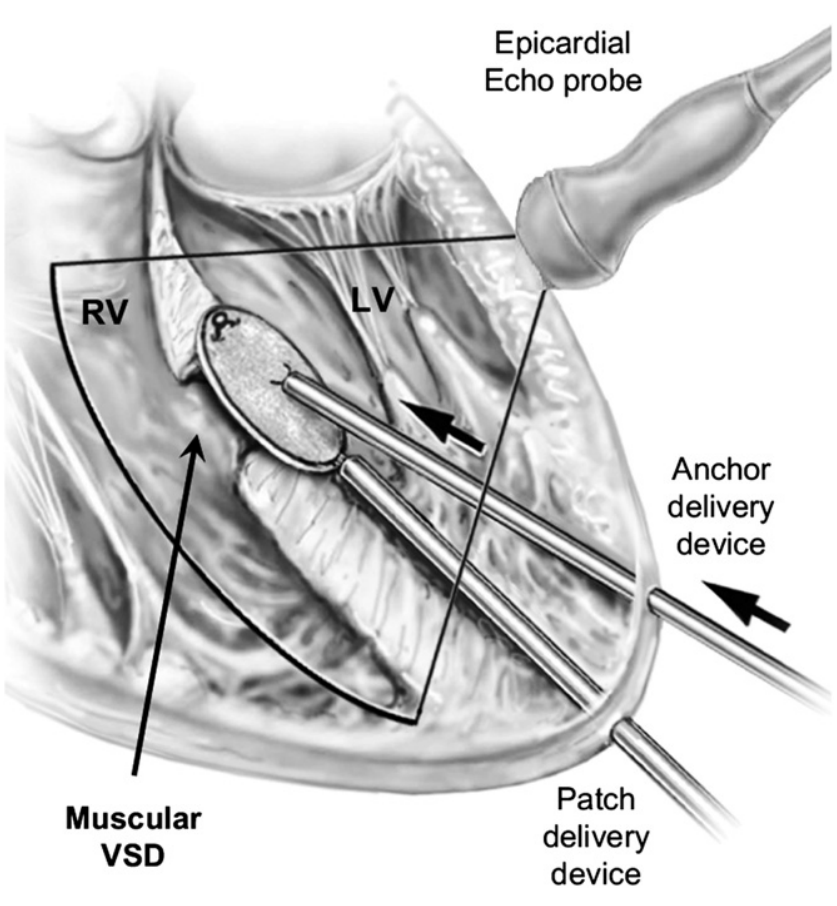

Figure 2. Scheme of the procedure. Explanations are shown in the text. $L V$, Left ventricle; $R V$, right ventricle; $V S D$, ventricular septal defect.

previously described. ${ }^{9}$ Briefly, the system includes 2 parts: the catheter-based patch delivery device and the patch fixation device. The patch delivery device consists of a self-expanding nitinol frame and a grip. A polyester patch is appropriately trimmed and then attached to the frame with a $0.1-\mathrm{mm}$ nitinol release wire (Figure $1, A$ and $B$ ). The device is delivered through a $9 \mathrm{~F}$ sheath, and the frame with the patch is deployed through the end of the sheath and allowed to expand. The polyester patch is attached to the septum by using nitinol minianchors (Figure 1,C) deployed with a pistol-type anchor delivery device.

The patch deployment device was introduced through a second 30 polypropylene purse-string suture in the LV and advanced toward the VSD under RT3DE guidance, staying parallel to the ventricular septum and away from the papillary muscles and the mitral valve chordae and leaflets. Once the frame with the patch was deployed and placed over the VSD, the fixation device was introduced into the LV and advanced toward the patch (Figure 2). The anchors were deployed by using a fixation device, one by one around the circumference of the patch. This latter maneuver was also performed under RT3DE guidance and in 2 steps. First, the arms of the anchor were deployed, and successful penetration of both the patch material and the septum was confirmed with tactile sensation and applying of gentle traction force on the deployed anchor. Next, the anchor loop was fully deployed, and the anchor was released from the fixation device. After the patch was fixed to the septum, the release wire was removed, allowing separation of the patch from the frame, and the frame was withdrawn into the sheath. This technique leaves only the polyester patch and nitinol anchors inside the heart. After
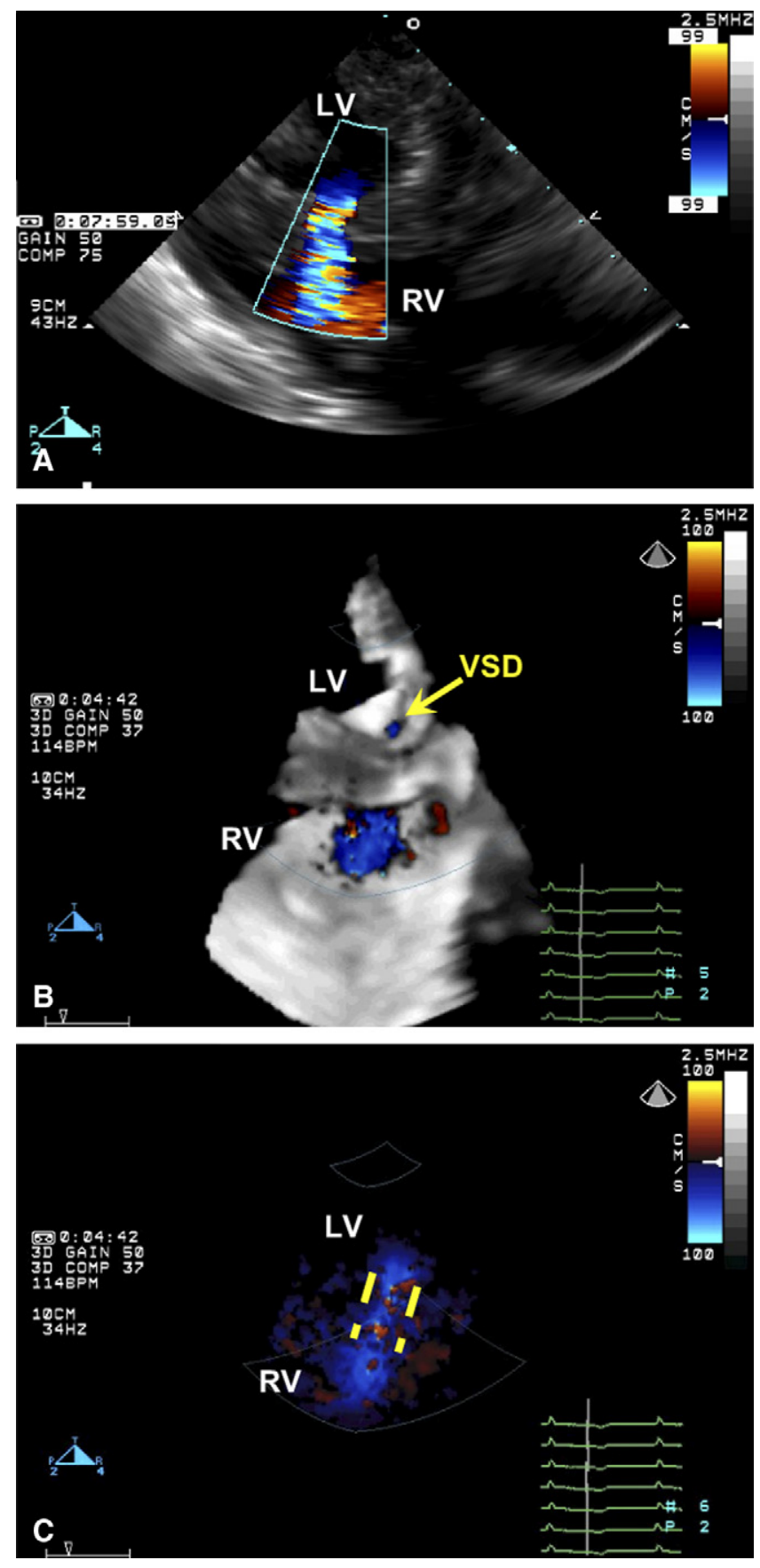

Figure 3. Color Doppler images of the created ventricular septal defect. A, Two-dimensional color Doppler scanning. B, Threedimensional color Doppler scanning. The yellow arrow points to the orifice of the ventricular septal defect on the left side of the ventricular septum. C, The same three-dimensional color Doppler image with suppression of the black-and-white image. Yellow dashed lines demonstrate the ventricular septal defect tunnel inside the ventricular septum. $L V$, Left ventricle; $R V$, right ventricle; VSD, ventricular septal defect. 
Ex vivo demo
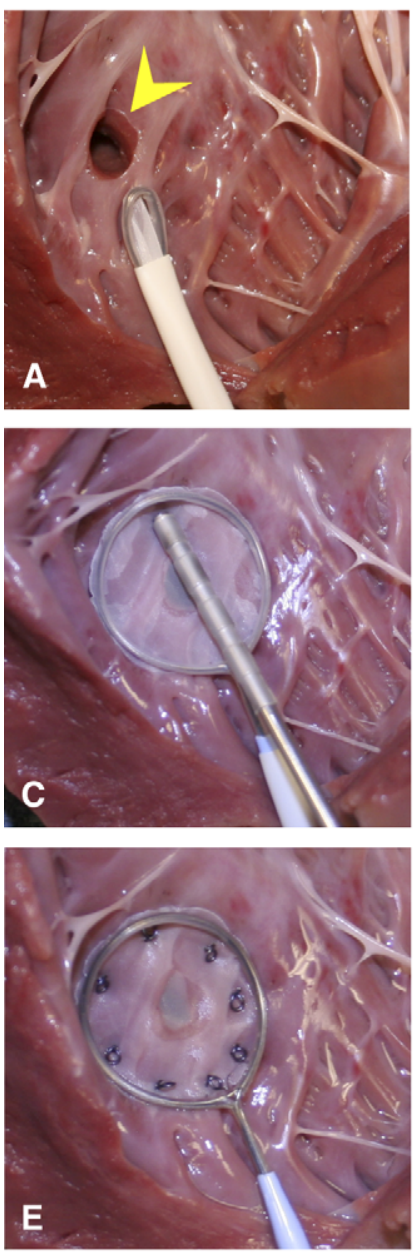
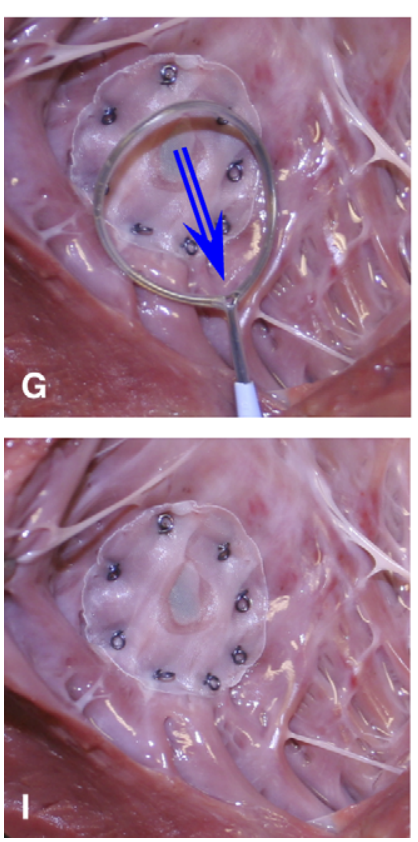

RT3DE in vivo
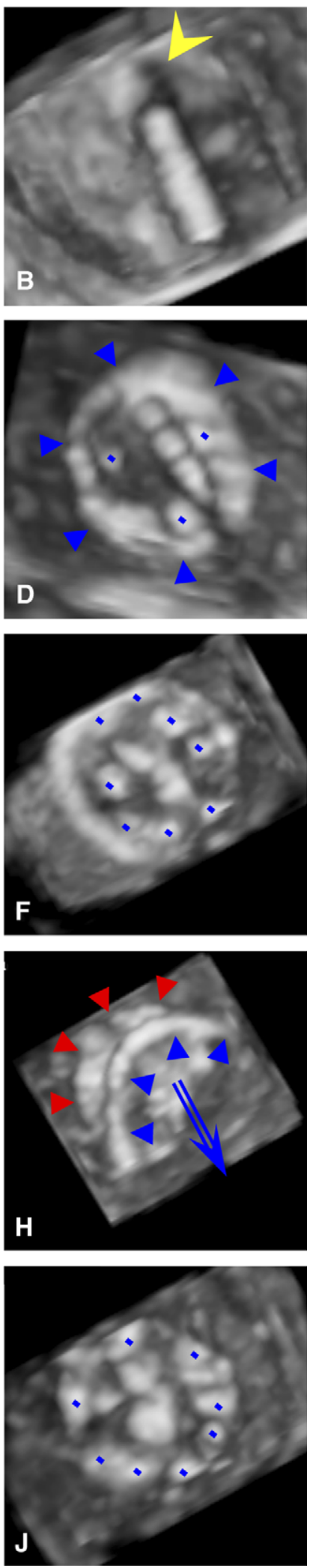

VSD closure, 2D and 3D color Doppler echocardiography was performed to look for any residual shunts. Finally, the animal was sacrificed, the heart was excised, and the efficacy of closure and patch fixation was determined by means of direct inspection.

\section{Results}

To safely perform the entire procedure solely under RT3DE guidance, the optimal orientation of the epicardial ultrasonographic probe and different insertion points for the devices was determined in the first 2 animals. The transducer was positioned at approximately $45^{\circ}$ to the surface of the left ventricular free wall, close to the atrioventricular groove, aiming toward the apex. With this orientation, nearly the entire left ventricular chamber was able to be visualized, and the devices could be navigated from the insertion points toward the ventricular septum under constant 3DUS monitoring. The devices were introduced coaxially into the LV from the apical region. This orientation provided optimal ergonomics for device manipulation, adequate visualization for safe device navigation inside the $\mathrm{LV}$, and minimized trauma of the left ventricular wall, avoiding the coronary arteries (Figure 2).

\section{VSD Creation}

The VSDs were created in the midventricular $(n=4)$, anterior $(\mathrm{n}=2)$, and apical $(\mathrm{n}=2)$ muscular septum. The mean size of the VSD was $9.8 \mathrm{~mm}(8.2-12.0 \mathrm{~mm})$, as determined by means of $2 \mathrm{D}$ color Doppler echocardiography (Figure $3, A$ ). Successful creation of the defects was also confirmed by means of 3D color Doppler echocardiography (Figure 3, $B$ and $C$ ). The size of the patch used was $20 \mathrm{~mm}$ in all the cases.

\section{VSD Closure}

Representative sequential RT3DE images obtained during VSD closure are shown in the right column of Figure 4; the left column shows ex vivo demonstration of the procedure for better comprehension. The VSDs were closed completely in 7 animals, with no residual shunts detected by means of

\footnotetext{
Figure 4. Ventricular septal defect patch closure demonstration ex vivo (left column) and sequence of the real-time three-dimensional echocardiographic (RT3DE) images acquired during the procedure (right column): view from the left ventricle. A and $B$, The patch is delivered through an introducer sheath toward the ventricular septal defect (yellow arrowhead). C and D, After the frame expands (blue arrowheads) and the patch covers the ventricular septal defect, it is attached to the ventricular septum by the nitinol minianchors (blue dots). Note the segmented polymer coating of the anchor-deployment device for optimizing the instrument visualization under ultrasonographic guidance. E and $F$, All the anchors are deployed, and the patch is completely attached to the septum, closing the ventricular septal defect. $G$ and $H$, The release wire is removed, and the frame is withdrawn into the introducer sheath. The patch (red arrowheads) is left attached to septum. I and J, Final view: patch and anchors (blue dots).
} 

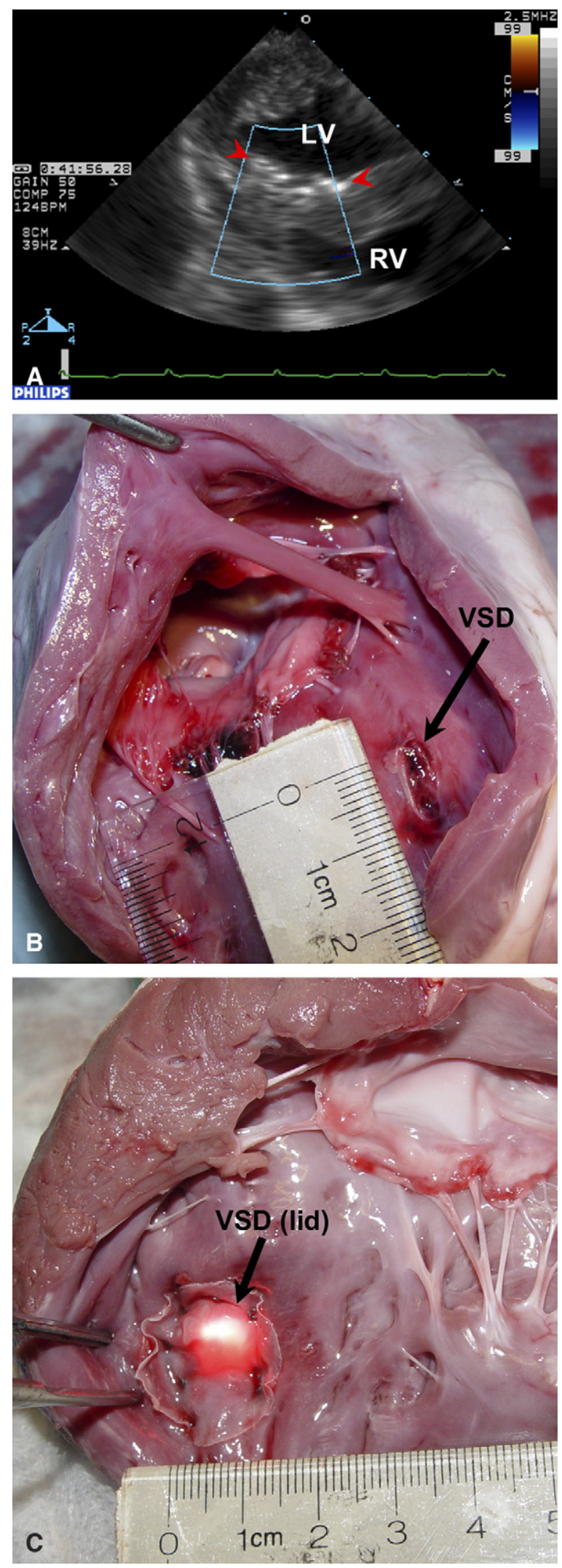

color Doppler scanning (Figure 5, A). A mean of 8 (range, 710) anchors was used per case. In one animal a 2.4-mm residual defect was identified around the edge of the patch. That animal had the largest VSD $(12 \mathrm{~mm})$ of the series, with the VSD having been created in the midventricular septum by means of repeated coring of the muscular tissue. As a result, the tissue around the VSD was porous and friable, and it was difficult to transfix the patch to the septum with the anchors.

Direct inspection of the septum after excision of the heart confirmed the intraoperative echocardiographic findings (Figure 5, $B$ and $C$ ). The anchors consistently penetrated the patch material and the ventricular septal myocardium. The VSDs were sealed completely in 7 cases. In one animal residual communication of $2 \mathrm{~mm}$ was found. No other anatomic structures in the LV and right ventricle were compromised in any of the cases.

\section{Discussion}

The present study demonstrates that (1) muscular VSDs can be successfully created in pigs by using a perventricular coring device and (2) muscular VSDs can be closed under RT3DE guidance on the beating heart through a left perventricular approach by using a patch anchored to the left side of the septum (see Video 1).

Closure of an isolated VSD is one of the oldest cardiac procedures, beginning with the first successful closure in 1955 by C. Walton Lillehei. ${ }^{13}$ The procedure currently enjoys a low complication and mortality rate, with surgical repair remaining the mainstay of therapy. Percutaneous device closure techniques have recently emerged and have had mixed success. ${ }^{14}$ Although device closure has been successfully applied in cases of multiple muscular VSDs or midmuscular isolated VSDs, for example, it has thus far not proved to be superior to cardiac surgery when it comes to complete closure of the defects. For membranous VSDs, development of complete heart block, sometimes occurring late after device implantation, has been a source of concern. ${ }^{15}$ Furthermore, the presence of an often bulky device in close proximity to the aortic valve and left ventricular outflow tract has the potential for resulting in other late complications. Furthermore, the chordae of the subvalvar apparatus of the mitral and tricuspid valves and the integrity of the aortic valve cusps are at risk during repeated passages of wires and sheaths into the heart. The perventricular techniques, developed clinically for muscular

Figure 5. A, Two-dimensional color Doppler image of the closed ventricular septal defect. The patch (red arrowheads) completely sealed the ventricular septal defect. B and C, Postmortem photographs: view from the right ventricle (B) and left ventricle (C). The patch is properly fixed around the $10-\mathrm{mm}$ ventricular septal defect. No residual defect is present. $L V$, Left ventricle; $R V$, right ventricle; VSD, ventricular septal defect. 
$\mathrm{VSDs}^{5}$ and in animal experiments for membranous VSDs, ${ }^{6}$ avoid some of these hazards, such as damage to the valves, because the VSD is approached directly at the ventricular level. No valves are crossed, and the angle of approach is close to $90^{\circ}$ to the plane of the septum, providing much more favorable conditions for crossing of the VSD and device deployment. However, perventricular device-based procedures still had significant drawbacks in terms of device bulkiness (eg, expansion in a hypertrophied right ventricular apex) or residual VSD from undersizing or malpositioning of the device. Devices themselves, as demonstrated from recent reports, ${ }^{16}$ can erode through cardiac structures, such as the aortic root. Endocarditis and thromboembolic episodes are other feared complications. ${ }^{17}$

The present procedure circumvents many of these complications. There is no need to first cross the VSD with a guidewire, one of the major initial difficulties in any device-based VSD closure. The catheter-mounted patch delivery device allows for a left-sided approach and is easily positioned and deployed over the VSD by using RT3DE. Because the patch is anchored on the left side of the septum, it is subjected to 4- to 5-fold higher pressure in systole, compressing it against the septal tissue, likely rendering small residual VSDs inconsequential in the long term. Unlike with open surgical repairs, in which sutures have to be closely aligned to prevent residual VSDs, anchors have to secure the patch in place but do not have to be very closely spaced. In our studies the anchors were secure and completely penetrated the muscular septal tissue. By virtue of its ventricular approach, this procedure retains the advantages of (right-sided) perventricular VSD closure, avoiding the crossing of valves. In addition, as opposed to the tricuspid valve, which has many septal attachments, there are no mitral valve papillary muscles based on the ventricular septum. This therefore provides more favorable conditions to operate in the beating-heart RT3DE-guided environment because there is no nearby subvalvular apparatus.

Compared with our previous experience of RT3DEguided ASD patch closure, ${ }^{9}$ we encountered few important technical differences between these 2 procedures. High velocity and contractile force of the ventricular septum, unlike atrial septal motion, makes free-hand deployment of the first anchors crucial, which in inexperienced hands can lead to torn myocardium and dislodged anchors. To address the problems with collision with the rapidly moving septum and to simplify anchor fixation to a moving target, we are developing a motion-compensation tool that tracks the motion of the septum in real time and might provide an easier method of patch fixation. ${ }^{18}$ Initial visualization and, more importantly, tracking of the muscular VSD with 3DUS imaging throughout the procedure is challenging. To address this problem, our group has developed an image-processing algorithm for block flow ASD detection and tracking. ${ }^{19}$ This technique has to be further optimized for real-time VSD tracking in a cluttered operative field in the left ventricular cavity. Finally, because there are no naturally occurring large-animal models of muscular VSDs, we developed this model using an original coring device to create the defects. The muscular VSDs were easily created by using the same entry point as was later used for the anchoring device. A final potential disadvantage is the possibility of pseudoaneurysm formation at the left ventricular free wall puncture site.

In summary, this study demonstrates that muscular VSDs can be successfully created and closed using our patch delivery device under RT3DE guidance on the beating heart in a large animal. In future work, we aim to test a similar technique for membranous VSD closure using Yucatan pigs. ${ }^{6}$

We thank Mr Randal S. McKenzie for the illustrations.

\section{References}

1. Menache CC, du Plessis AJ, Wessel DL, Jonas RA, Newburger JW. Current incidence of acute neurologic complications after open-heart operations in children. Ann Thorac Surg. 2002;73:1752-8.

2. Lichtenstein SV, Cheung A, Ye J, Thompson CR, Carere RG, Pasupati S, et al. Transapical transcatheter aortic valve implantation in humans: initial clinical experience. Circulation. 2006;114:591-6.

3. Walther T, Falk V, Borger MA, Dewey T, Wimmer-Greinecker G, Schuler G, et al. Minimally invasive transapical beating heart aortic valve implantation-proof of concept. Eur J Cardiothorac Surg. 2007;31:9-15.

4. Schreiber C, Horer J, Vogt M, Fratz S, Kunze M, Galm C, et al. A new treatment option for pulmonary valvar insufficiency: first experiences with implantation of a self-expanding stented valve without use of cardiopulmonary bypass. Eur J Cardiothorac Surg. 2007;31:26-30.

5. Bacha EA, Cao QL, Starr JP, Waight D, Ebeid MR, Hijazi ZM. Perventricular device closure of muscular ventricular septal defects on the beating heart: technique and results. J Thorac Cardiovasc Surg. 2003;126:1718-23.

6. Amin Z, Danford DA, Lof J, Duncan KF, Froemming S. Intraoperative device closure of perimembranous ventricular septal defects without cardiopulmonary bypass: preliminary results with the perventricular technique. J Thorac Cardiovasc Surg. 2004;127:234-41.

7. Suematsu Y, Takamot S, Kaneko Y, Ohtsuka T, Takayama H, Kotsuka Y, et al. Beating atrial septal defect closure monitored by epicardial real-time three-dimensional echocardiography without cardiopulmonary bypass. Circulation. 2003;107:785-90.

8. Suematsu Y, Martinez JF, Wolf BK, Marx GR, Stoll JA, DuPont PE, et al. Three-dimensional echo-guided beating-heart surgery without cardiopulmonary bypass: atrial septal defect closure in a swine model. J Thorac Cardiovasc Surg. 2005;130:1348-57.

9. Vasilyev NV, Martinez JF, Freudenthal FP, Suematsu Y, Marx GR, del Nido PJ. Three-dimensional echo and videocardioscospy guided atrial septal defect closure. Ann Thorac Surg. 2006;86:1322-6.

10. Lang RM, Mor-Avi V, Sugeng L, Nieman PS, Sahn DJ. Three-dimensional echocardiography: the benefits of the additional dimension. J Am Coll Cardiol. 2006;48:2053-69.

11. Ryan LP, Salgo IS, Gorman RC, Gorman JH. The emerging role of three-dimensional echocardiography in mitral valve repair. Semin Thorac Cardiovasc Surg. 2006;18:126-34.

12. Huang J, Triedman JK, Vasilyev NV, Suematsu Y, Cleveland RO, Dupont PE. Imaging artifacts of medical instruments in ultrasoundguided interventions. J Ultrasound Med. 2007;26:1303-22.

13. Lillehei CW, Cohen M, Warden HE, Ziegler NR, Varco RL. The results of direct vision closure of ventricular septal defects in eight patients by means of controlled cross circulation. Surg Gynecol Obstet. 1955;101: 446-66.

14. Holzer R, Balzer D, Cao QL, Lock K, Hijazi ZM. Amplatzer Muscular Ventricular Septal Defect Investigators. Device closure of muscular ventricular septal defects using the Amplatzer muscular ventricular septal 
defect occluder: immediate and mid-term results of a U.S. registry. $J$ Am Coll Cardiol. 2004;43:1257-63.

15. Holzer R, de Giovanni J, Walsh KP, Tometzki A, Goh T, Hakim F, et al. Transcatheter closure of perimembranous ventricular septal defects using the Amplatzer membranous VSD occluder: immediate and midterm results of an international registry. Catheter Cardiovasc Interv. 2006;68: 620-8.

16. Mello M, Fahey J, Kopf GS. Repair of aortic-left atrial fistula following the transcatheter closure of an atrial septal defect. Ann Thorac Surg. 2005;80:1495-8.
17. Scheuerman O, Bruckheimer E, Marcus N, Hoffer V, Garty BZ. Endocarditis after closure of ventricular septal defect by transcatheter device. Pediatrics. 2006;117:e1256-8.

18. Kettler DT, Plowes RD, Novotny PM, Vasilyev NV, del Nido PJ, Howe RD. An active motion compensation instrument for beating heart mitral valve surgery. Proc IEEE Intell Robots Syst. 2007. In press.

19. Linguraru MG, Vasilyev NV, del Nido PJ, Howe RD. Atrial septal defect tracking in 3D cardiac ultrasound. Med Image Comput Assist Interv. 2006;9:596-603. 